\title{
LOS HARO DE CAMEROS EN LOS SIGLOS XIII Y XIV ANÁLISIS DEL PROCESO DE SU AFIANZAMIENTO POLfTICO EN EL ÁMBITO REGIONAL
}

\author{
Máximo Diago Hernando \\ Universidad Complutense (Madrid)
}

\begin{abstract}
SUMARIO
1. Presencia política de Alfonso López de Haro en Rioja y Cameros.- 2. Actividad política de Juan Alfonso de Haro I durante los reinados de Alfonso X y Sancho IV.- 3. La actividad política de Juan Alfonso de Haro I durante el reinado de Femando IV.- 4. Las "malfetrías" de Juan Alfonso de Haro II en la Rioja durante la minoría de Alfonso XI.- 5. Ajusticiamiento de Juan Alfonso de Haro y posterior trayectoria de su linaje en Rioja y Cameros.
\end{abstract}

Resulta bien sabido que el linaje de los Haro fue uno de los más destacados de la llamada nobleza vieja castellana, y que hasta el siglo XIV represent $\sigma$ la principal instancia de poder en un amplio sector del nordeste del reino de Castilla fronterizo con Navarra, del que formaba parte importante el propio territorio riojano ${ }^{1}$.

${ }^{1}$ No existen obras monográficas recientes dedicadas al linaje de los Haro de Vizcaya. Entre las antiguas hay que destacar la de Luis DE SALAZAR Y CASTRO, Historia genealógica de la Casa de Haro, Madrid, 1920. Para su encuadramiento entre los linajes de la nobleza vieja, vid. S. DE MOXO, De la nobleza vieja a la nobleza nueva. La transformación nobiliaria castellana en la Baja Edad Media, "Cuademos de Historia. Anexos a la Revista Hispania, 3 (1969), pp. 1-210. Sobre su papel en los origenes del señorio vizcaíno vid. A.E. DE MANARICUA, Vizcaya, siglos VIII al XI. Los origenes del señorio, Bilbao, 1984, pp. 292 y 88 . Más referencias a su papel en el ámbito riojano contiene D. HERGUETA, Historia de Haro, Madrid, $1969,2^{\star}$. ed. Y por fin J. DE LEZA, Los López Diaz de Haro, seriores de Vizcoya y los señores de Cameros en el gobiemo de la Rioja durante la Edad Media (1016-1334), Logroño, 1954. 
Durante el siglo XIII, sin embargo, tuvo lugar un proceso de consolidación en este último territorio de una rama menor del linaje, que logró hacerse con el control del antiguo señorío de Cameros, y que gracias a éste y a otros muchos factores consiguió desplazar en gran medida a los representantes de la rama primogénita de la posición de preeminencia política que desde hacía bastante tiempo venían ocupando los señores de Vizcaya en tierras riojanas, llegando el proceso a su culminación en las últimas décadas del siglo XIII y primeras del XIV. Ciertamente el núcleo territorial desde el que estos Haro de Cameros se impusieron en esta época como linaje hegemónico, en el referido ámbito geográfico, experimentó un cierto desplazamiento hacia la Rioja Baja, mientras los Haro de Vizcaya continuaban manteniendo una cierta influencia sobre la comarca de la Rioja Alta, y los dos grandes monasterios de la zona, el de San Millán de la Cogolla y el de Santa María de Nájera².

El análisis del proceso de afianzamiento de esta rama menor de los Haro de Cameros en territorio camerano-riojano, aunque ciertamente ya ha sido abordado de forma parcial por muy diversos autores ${ }^{3}$, no ha despertado sin embargo un interés notable entre los historiadores de las últimas décadas. $Y$ por ello siguen siendo numerosos los equivocos y las incertidumbres en torno a la fijación de los hechos positivos en que se fue plasmando en sus diferentes etapas, por no hablar de su interpretacion en un marco de reconstrucción de los procesos de articulación político-territorial

\footnotetext{
${ }^{2}$ El señor de Vizcaya, Lope Díaz de Haro, fue tomado como encomendero y protector por el monasterio de Santa María de Nájera en 1275, que a cambio le entregó San Martín de Azo y Santa María de Estríbaliz. Vid. el documento de cesión de estas propiedades por el monasterio, fechado el 7-VII-1275 en AHN, Códice 106-B, fol. 27. Su hermano y sucesor, Diego López de Haro, continuó ejerciendo influencia sobre este mismo monasterio, y así lo prueba el qeu en 1298 prometiese a su prior entregarle a su muerte la casa de Cuevacardiel, que de él tenía recibida. Vid. I. RoDRIGUEz R.DE LAMA, Colección Diplomática Medieval de la Rioja, t. IV, Logroño, 1990, doc. $\mathrm{n}^{0} .528$ (Valladolid, 4-III-1298). A este mismo señor de Vizcaya estaría entregado en encomienda en 1299 el monasterio de San Millán de la Cogolla, según noticia proporcionada por J.A. GARClA DE COSTÁZAR, El dominio del monasterio de San Millán de la Cogolla (Siglos X-XIII), Salamanca, 1969, p. 345.

${ }^{3}$ Hay que destacar J. DE LEZA, op. cit. Tambien contiene datos al respecto E. GONZALEZ CREsPo, Los Arellano y el seriorfo de los Cameros en la Baja Edad Media, "En la España Medieval", II (1982), t. I, pp. 395-410. Y nuestro artículo Implantación territorial del linaje Arellano en tierras camero-riojanas a fines de la Edad Media, "Berceo", 120 (1991), pp. 68 73. Por fin, y sin ánimo de ser exhaustivos, también hay que mencionar el artículo de E. REINARES MARTINEZ, Apuntes para la historia de San Román y su Tierra en el Cameros Viejo, "Berceo", 118-119 (1990), pp. 149-180.
} 
del reino de Castilla en los siglos XIII y XIV, que hasta ahora apenas ha sido abordada por nadie.

Advirtiendo, pues, la existencia de este vacío epistemológico, y aprovechando el haber reunido en el transcurso de nuestras investigaciones durante los últimos años un conjunto relativamente importante de noticias documentales dispersas, de interés para esta cuestión, hemos estimado oportuno proponer aqui una reconstrucción de este proceso desde las primeras décadas del siglo XIII hasta después del ajusticiamiento de Juan Alfonso de Haro II por orden de Alfonso XI, con el ánimo de contribuir al análisis de la vida política regional en los distintos ámbitos del reino de Castilla durante una de las épocas más marcadas por el expansionismo nobiliario.

\section{Presencia polftica de alfonso lópez de haro EN RIOJA Y CAMEROS}

Alfonso López de Haro era hijo del señor de Vizcaya, el conde Don Lope Draz de Haro, y de doña Urraca, hermana del rey Fernando III $^{4}$. Su padre ya habla ocupado las principales posiciones de poder en la Rioja durante el primer cuarto del siglo XIII, apareciendo identificado en muy diversos documentos como tenente de Calahorra, Logroño, Najera y Riojas. Y su especial vinculación con este ámbito geográfico quedó ratificada con su elección del monasterio de Santa Marra de Nájera para su enterramiento ${ }^{6}$.

A la muerte de este señor de Vizcaya, acaecida en el año 1236, su hijo primogénito Diego López de Haro no consiguio sucederle en sus tenencias riojanas, que sólo en parte fueron a parar a manos de su hermano menor Alfonso Lopez de Haro, a quien la documentación conservada ya presenta como señor de Calahorra desde $1237^{7}$ y como señor de Nájera y p. 484.

4L. De Salazar y CASTro, Historia Genealógica de la Casa de Lara, Madrid, 1696, I,

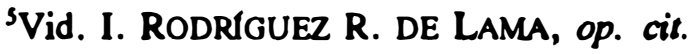

'Tomamos la noticia de D. Hergueta, op. cit. p. 84.

7Vid. I. RODRfGUez R. DE LAMA, op. cit. doc. $n^{0} .119$. 
su Tierra desde $1239^{8}$. No obstante, la rama primogénita de los Haro, señores de Vizcaya, pronto volví a recuperar gran parte de la presuntamente perdida influencia sobre esta región, sólo que preferentemente en el sector de las merindades de Rioja y Nájera, de forma que el sucesor de Diego López de Haro, el favorito de Sancho IV Lope Díaz de Haro, consta que fue prestamero de Rioja y Bureba9, y que fue escogido como encomendero y protector por el monasterio de Santa María de Nájera, en $1275^{10}$.

De hecho Lope Díaz de Haro fue un noble que llegó a acumular mucho poder gracias a su inicial vinculación con Sancho IV, y nada tiene, por consiguiente, de excepcional que también tratase de continuar con la línea de sus antepasados, imponiendo su autoridad en el territorio riojano. Pero lo que más nos llama la atención es advertir que no consta que, como consecuencia de este proceso de fortalecimiento de su posición tanto en la Corte como en la región, su tío Alfonso López de Haro viese amenazada su recientemente adquirida hegemonía en tierras riojanas, que como hemos adelantado tendía a concentrarse en el sector de la Rioja Baja. Lamentablemente, no disponemos de elementos de información suficientes para determinar cómo fueron las relaciones de tío y sobrino durante los reinados de Alfonso X y Sancho IV, pero en cualquier caso la definitiva carda en desgracia y ajusticiamiento del primero por este último monarca llevó a que la capacidad del ejercicio del poder por parte de la rama primogénita del linaje Haro en territorio riojano quedase considerablemente mermada, aunque no totalmente anulada, a juzgar por las noticias que nos presentan a los señores de Vizcaya ejerciendo todavía cierta autoridad sobre los monasterios de San Millán de la Cogolla y Santa María de Nájera enlos últimos años del siglo XIII ${ }^{11}$. Y fueron el hijo y nierto de Alfonso López de Haro los que mejores frutos obtuvieron de este cambio de tendencia, al librarse de la tutela de los representantes de la rama primogénita y como consecuencia pasar a establecer las bases para el ejercicio del poder en la región desde una posición más independiente.

\footnotetext{
${ }^{8}$ Ibid. doc. $\mathrm{n}^{0} .128$.

${ }^{9}$ loid. doc. n'. 429.

${ }^{10} \mathrm{Cf}$. nota 2.

${ }^{11} \mathrm{Cf}$. nota 2 .
} 
Pero, para seguir un orden cronológico, hemos de detenernos previamente en el análisis de la figura política de Alfonso López de Haro, quien, aunque presumiblemente viviese a la sombra de sus parientes mayores de Vizcaya, consiguió para sus descendientes importantes logros en el proceso de afianzamiento político del linaje en Cameros y Rioja Baja.

Para empezar, su posición como tenente o señor de Calahorra y Nájera quedó notablemente reforzada gracias a su matrimonio con Marfa Alvarez de los Cameros, hija del señor de Cameros, Álvar Díaz, y de Doña Aldonza Díaz de $\mathrm{Haro}^{12}$. Todos los autores han visto en este matrimonio el origen de la consolidación del linaje de Haro como segundo linaje de señores de Cameros, después de los Fortuniones y antes de los Arellano. Pero en la secuencia de acontecimientos que llevaron a la misma que proponen algunos de los referidos autores, se advierten bastantes lagunas y equivocos, resultantes en gran medida de la aplicación a la caracterización del antiguo señorfo de Cameros de categorías propias de época Trastamara, que ha llevado a entender que éste constituía ya en los siglos XII y XIII un compacto y homogéneo territorio señorial que se transmitía indiviso dentro del linaje de los Fortuniones por derecho de primogenitura ${ }^{13}$.

Si se admite este punto de vista, y se acepta que el señorío de Cameros quedo vacante en 1277 , cuando Simón Ruiz fue ajusticiado por orden regia acusado de traicion ${ }^{14}$, se nos plantea entonces no obstante el problema de explicar cómo mucho antes de producirse esta muerte, concretamente en 1246, Alfonso López de Haro y su mujer María Álvarez de los Cameros pudieron dotar al monasterio de monjas cistercienses fundado por ellos en Herce con los señoríos de esta propia villa y de Murillo de Calaho-

\footnotetext{
${ }^{12} \mathrm{Cf}$. nota 4.

${ }^{13}$ Este punto de vista es el que sostiene E. GONZÁLEZ CRESPO, en op. cit., al afirmar que Cameros fue, al igual que Vizcaya y Molina, uno de los territorios señoriales más extenso y compacto de la Castilla pretrastamara, calificándolo literalmente como "uno de los de carácter territorial más continuo y homogéneo de la Vieja Castilla". Los escasos documentos disponibles que informan sobre el carácter de este señorío en los siglos plenomedievales no corroboran este punto de vista, sino que más bien hacen pensar que el señorio constituía una amalgama de derechos muy heterogéneos ejercidos sobre diversidad de lugares, que bajo ningún concepto conformaban un compacto y homogéneo territorio. $Y$, de hecho, esta falta de unidad del conjunto territorial sobre el que se ejercía el señorio se continuó advirtiendo en época Trastamara, cuando los Arellano se hicieron con el control de gran parte de la herencia de los Haro en Cameros. Vid. nuestro artículo Implaniación territorial.
}

${ }^{14}$ Vi. E. GonZÁlez Crespo, op. cil. p. 396. 
rra, La Santa y Torremuña, además de los collazos de Hornillos ${ }^{15}$. Muy probablemente Simon Ruiz controlaría la mayor parte de los señoríos cameranos correspondientes a su linaje y se reservaria para si hasta su muerte el título de señor de Cameros, que probablemente no tendría una referencia territorial perfectamente definida ${ }^{16}$. Pero al mismo tiempo su prima María Álvarez de los Cameros, reforzada en su posición política por estar casada con el tenente de Calahorra y Najera, controlaría ya en vida de éste junto con su marido algunos de los señoríos que a lo largo de los siglos habra adquirido el linaje de los Fortuniones, y que le corresponderfan por derecho de herencia.

Mucho más difícil resulta, sin embargo, admitir que tras la muerte de Simon Ruiz de los Cameros parte de sus señorfos fue donada al infante Don Pedro y otra devuelta a Maŕa Álvarez, como prima del difunto, puesto que presumiblemente ésta debia haber fallecido hacía bastantes años, dado que su marido aparece ya en 1257 casado con Sancha Gil, hermana del Adelantado Mayor de Castilla, Don Pedro de Guzmán ${ }^{17}$.

En todo caso habría podido ser Alfonso López de Haro quien recibiese los señoríos correspondientes a su difunta esposa, y el hecho de que en una fuente documental se le llegue a llamar señor de Cameros asl parece sugerirlo ${ }^{18}$; pero dado el carácter poco fiable de esta fuente quizás sea más prudente pensar que fuese su hijo mayor Juan Alfonso de Haro quien recibiese la herencia materna.

\footnotetext{
${ }^{15}$ Vid. nuestro artículo Un monasterio cisterciense femenino en tierras riojanas. Herce entre los siglos XIII y XVI, "Cistercium", 188 (1992), pp. 130 y 88.

${ }^{16} \mathrm{Cabe}$ incluso presumir que la referencia "señor de Cameros" tuviese el mismo carácter que las abundantes referencias que aparecen en la documentación riojana del siglo XIII a señores y "dominantes" de lugares como Calahorra o Nájera, que nadie se atrevería a identificar con auténticos señorios, puesto que quienes se identifican con esos títulos tenian preferentemente el carácter de tenentes nombrados a título precario por la monarquía. El propio Simón Ruiz, último señor de Cameros de su linaje, aparece identificado en ocasiones en la documentación riojana como señor de Quel y de San Pedro (Actual San Pedro Manrique, en la provincia de Soria), entendiéndose que su papel en estas dos villas era preferentemente el de tenente.

${ }^{17}$ La noticia sobre el reparto de Cameros tras la muerte de Simón Ruiz, en E. GONZALrz CRESPO, op. cit. p. 396. Sobre el matrimonio con Sancha Gil, vid. nuestro artículo Un monasterio cisterciense, pp. 131-2.

${ }^{18}$ Vid. I. RODRIGUEZ R. DE LAMA, op. cit., doc. $n^{0}$. 552 . Se identifica en este documento sin fecha a Alfonso López de Haro como señor de Los Cameros y de Murillo. Dado que se trata de una información redactada a posteriori por interés de unas iglesias parroquiales de Calahorra, entra dentro de lo posible que se le atribuyese un título que en realidad no ostentó, confundiendo su posición con la de su hijo Juan Alfonso.
} 
Pero, sea como fuere, lo cierto es que Alfonso Lopez de Haro tras enviudar de su primera esposa continuo avanzando en su afianzamiento político en la región riojana, según demuestran algunas noticias documentales dispersas, lamentablemente muy escasas. Y asf llama la atencion advertir en primer lugar que Murillo de Calahorra, donado por él y su esposa al monasterio de Herce en el año de su fundación, volvió a ser ocupado por el propio Alfonso López de Haro en fecha no determinada con precision ${ }^{19}$. Del mismo modo también consta que éste y su segunda esposa, Sancha Gil, tuvieron tomado al monasterio de Santa Marra de Nájera su lugar de Torrecilla de Cameros ${ }^{20}$; y que por fin recibieron por merced de Alfonso X, en 1257 , con nueva ratificación en 1260 , la villa de Viliella de Ocón, con sus aldeas, que luego fueron donadas por ellos en su conjunto en 1261 al monasterio de $\mathrm{Herce}^{21}$.

En sus relaciones con los monasterios no dejo, pues, de demostrar Alfonso López de Haro una actitud ambivalente, puesto que mientras por un lado les efectuaba sustanciosas donaciones, por otra no dudaba en tomar para sl algunas de sus propiedades. Pero en conjunto, y a largo plazo, quizás tuvieron mayor trascendencia las donaciones que las usurpaciones, por lo que a este respecto Alfonso López de Haro respondió más a la actitud propia de la alta nobleza castellana plenomedieval, muy generosa en la docación de señorfos a monasterios, que a la manifestada por los linajes nobles en la Baja Edad Media, que salvo excepciones actuaron como depredadores de los patrimonios señoriales monásticos ${ }^{22}$.

\footnotetext{
${ }^{19} \mathrm{Cf}$. doc. cit. en nota anterior. Por otro documento nos consta, sin embargo, que la abadesa de Herce, Elvira Martínez, accedió a dejar en poder de Juan Alfonso de Haro el lugar de Murillo de Calahorra a cambio de 6.000 mrs. Vid. Un monasterio cisterciense, p. 132.

${ }^{20}$ Así lo reconocieron en una donación efectuada al prior de Nájera en 1261 de un palacio, rueda y heredades en Torrecilla de Cameros, en recompensa "por la gratia que vos nos ficiestes en la villa de Torreziella, que nos diestes para en nuestros días".

Vid. I. RODRIGUEZ R. DE LAMA, op. cit. doc. no. 253.

${ }^{21}$ Vid. Un monasterio cisterciense, pp. 131-132.

${ }^{22}$ Desarrollamos más extensamente esta idea en nuestro artículo El intervencionismo nobiliario en los monasterios riojanos durante la Baja Edad Media. Encominedas y usurpaciones, "Hispania", 182 (1992), pp. $811-61$.
} 


\section{Actividad politica de Juan Alfonso de HaRo I duRANTE LOS REINADOS DE ALFONSO X Y SANCHO IV}

Resulta difícil determinar con precisión la fecha de la muerte de Alfonso Lope de Haro, pero varios indicios documentales prueban que ya en vida cedió a su hijo primogénito, Juan Alfonso de Haro, algunos de sus principales posiciones de poder, y muy en particular la tenencia de Calahorra, que era controlada por este último en $1263^{23}$. Por otra parte, a fines de esa misma década consta que éste estaba también ya percibiendo ciertos derechos señoriales en el ámbito camerano, probablemente quizás por habérselos transferido la propia monarquia ${ }^{24}$. Y, por fin, otro indicio, que nos revela que ya en estas fechas tempranas de su carrera política ejercía notable influencia en el territorio riojano, nos la proporciona un documento del año 1272 en el que conjuntamente con su esposa Constanza Alfonso reconocieron al monasterio de Santa María de Nájera la propiedad de la villa de Urturi, que probablemente le habran usurpado en fechas anteriores $^{25}$. De hecho, según el propio documento, el que accediesen a efectuar este reconocimiento obedecía sobre todo al deseo de librar sus almas y las de sus padres de pecado, por lo que cabe presumir que tanto Alfonso Lopez de Haro como su hijo Juan Alfonso estuvieron usurpando propiedades al monasterio najerense. Y, al mismo tiempo; gracias también a esta fuente documental, nos consta que la práctica inaugurada por el primero de arrancar a este mismo monasterio concesiones de por vida de algunos de sus principales lugares de señorío fue proseguida por su hijo, quien reconoció que habra recibido con estas condiciones la villa de Santurdejo.

\footnotetext{
${ }^{23}$ Para la identificación de Juan Alfonso de Haro como señor de Calahorra en 1263, vid. I. RODRfGUEZ R. DE LAMA, op. cit. doc. $n^{\circ}$. 262. Queda fuera de toda duda que para esa fecha seguía viviendo su padre Alfonso López de Haro porque éste aparece como señor de Nájera y de toda su Tierra en 1264 (Ibid. doc. $n^{0}$. 267).

${ }^{24}$ En 1269, Juan Alfonso de Haro reconoció que no le correspondía cobrar la martiniega en Torrecilla de Cameros, porque el prior y convento de Santa María la Real de Nájera le mostraron que los reyes les habían donado esta villa "quita et libre de toda demanda real". Por consiguiente, ordenó a sus merinos y a todos los que cobraban por él sus derechos que no demandasen nada a este concejo. Publica el doc. I. RODRfGUEZ R. DE LAMA, op. cit. doc. $n^{0} .296$.

${ }^{25}$ Vid. I.RODKIGUEZ R. DE LAMA, op. cit. doc. $n^{0} .322$ (17-VII-1272).
} 
Por lo demás no resulta fácil llegar a determinar con precisión cuál fue la actitud de Juan Alfonso de Haro con ocasión de los enfrentamientos entre Alfonso $\mathrm{X}$ y su hijo el infante Sancho, aunque algún indicio invita a sospechar que permanecio fiel al primero, a diferencia de su primo Lope Díaz de $\mathrm{Haro}^{26}$. Y en este sentido apunta en particular el privilegio que Sancho IV, siendo ya rey de Castilla, otorgo en Soria el 12 de febrero de 1285 al concejo de Logroño, confirmándole uno anterior que le habra otorgado siendo infante, por el que le concedía a esta ciudad el castillo y la villa de Clavijo, en recompensa por haber tomado esta fortaleza del poder de Juan Alfonso de Haro ${ }^{27}$.

En cualquier caso parece seguro que las relaciones entre Sancho IV y Juan Alfonso de Haro pronto se normalizaron, si es que con anterioridad se había llegado a algún tipo de ruptura, y así lo demuestra por ejemplo el que en 1288 este último percibiese determinados derechos pertenecientes a la fiscalidad regia, por habérselos transferido el monarca en concepto de tierra, en los siguientes lugares: Nájera, Calahorra, Arnedo, Alfaro, Autol, Yanguas, Ágreda, Cervera, Aguilar y Berlanga de Duero ${ }^{28}$. Al mismo tiempo continuo figurando en los documentos como señor de Calahorra, si bien parece seguro que ya en vida transfirio este puesto a su hijo primogénito Juan Alfonso de Haro II, al que se puede identificar como señor de esta ciudad al menos desde $1298^{29}$. Pero, en contrapartida, paradojicamente ninguno de los dos llegan a ser identificados en la documentación consultada como señores de Nájera, a diferencia de Alfonso López de Haro, por

\footnotetext{
${ }^{26}$ Por haber tomado partido Lope Díaz de Haro por el infante Don Sancho le privó Alfonso $\mathrm{X}$ en 1282 del señorío de Haro, que entonces entregó al infante Don Jaime, muerto al año siguiente. Vid. D. HERGUETA, op. cit. p. 86.

${ }^{27}$ RAH, Salazar y Castro, 0-16, fol. 227. Vid. también J. RUIz NAVARRO, El castillo de Clavijo, "Cuademos de investigación histórica. Brocar" (En la sucesivo "Brocar"), 16 (1990), pp. $51-60$.

${ }^{28}$ Según documento del archivo municipal de Logroño de 16-XII-1288, en que Juan Alfonso de Haro se dirige a "todos aquellos que tienen de mi por tierra los derechos que yo tengo del rey en Nájera, Calahorra, Amedo, Alfaro, Abtol, Yanguas, Ágreda, Cervera, Aguilar, Berlanga e en todos los otros logares de Castiella que yo tengo del rey por tierra, a todos los portazgueros", para que no cobrasen portazgo a los vecinos de Logroño. Publica M. GAIBROIS DE BAULESTEROS, Sancho IV de Castilla, III, Madrid, 1928, doc. $\mathrm{n}^{\circ} .228$.

${ }^{29}$ Frecuentemente resulta difícil diferenciar a cuál de los dos Juan Alfonso de Haro se refieren los documentos. Pero es seguro que el que aparece identificado como señor de $\mathrm{Ca}$ lahorra en un documento de 3-IV-1298 es el hijo, porque se indica que su mujer era Teresa de Almoravit, y que ésta hacía las funciones de subtenente. Literalmente, el documento reza así: "Sennor en Calahorra don Johan Alonso, so el domna Teresa Almoravit su mugier". Vid. I. RODRIGUEZ R. DE LAMA, op. cit. doc. $n^{0}$. 529.
} 
lo que es bastante probable que se les retirase la tenencia de esta importante ciudad, aunque el hecho de que no hemos podido identificar otros tenentes para las últimas décadas del siglo XIII y primeras del XIV nos obliga a mostrarnos muy precavidos a la hora de adelantar cualquier conclusión, en tanto no se encuentren más datos que arrojen nueva luz sobre la cuestión.

Por lo demás, prueba suficientemente que Juan Alfonso de Haro llego a gozar de la confianza de Sancho IV, y gracias a ello afianzo considerablemente su posición de poder en là Rioja Baja, el hecho de que, al firmarse en 1291 en Monteagudo-Soria el tratdo de paz entre este monarca y Jaime II de Aragón, se le eligió a él para que controlase tres de los castillos escogidos como garantía para su cumplimiento, que fueron en concreto los de Cervera, Alfaro y Agreda $^{30}$.

Pero, a pesar de los logros conseguidos, habra de ser tras la muerte de Sancho IV cuando la figura politica de este señor de Cameros conociese su promoción más fulgurante.

\section{La actividad política de Juan Alfonso de Haro I DURANTE EL REINADO DE FERNANDO IV}

Los primeros años que siguieron a la muerte de Sancho IV representaron un momento muy favorable para la carrera política de Juan Alfonso de Haro, quien consiguió afianzar su posición de poder en la Rioja de forma notable, aprovechando no obstante bases ya sentadas en reinados anteriores. Y fueron en particular las dificultades con las que se enfrento la monarquía durante la minoría de Fernando IV las que de forma más decisiva contribuyeron a incrementar su poderío en la región riojana, porque la reina regente, a fin de contar con apoyos suficientes con los que hacer frente a la nobleza levantisca, se vio forzada a premiar los servicios de los nobles que le permanecieron fieles. Y el ejemplo de Juan Alfonso de Haro es uno de los que mejor ilustra esta práctica.

En los primeros momentos del nuevo reinado la posición política de este noble debió ser un tanto inestable en el territorio camerano-riojano, puesto que según una noticia cronística se deduce que entonces no controla-

\footnotetext{
${ }^{30}$ Según el texto del tratado entre Sancho IV y Jaime II, que publica M. GAIBROIS DE BALLESTEROS, op. cit., III, doc. $n^{\circ} .384$.
} 
ba el señorío de los Cameros ${ }^{31}$. La reina, no obstante, al peligrar la posición en el trono de su hijo, cuando Castilla fue invadida desde Portugal y Aragón y el infante Juan se proclamó rey de León, solicitó el auxilio de diversos nobles que ella consideraba fieles, entre los que figuraba Juan Alfonso de Haro, y con toda probabilidad fue esta coyuntura la que le permitió a éste forzar la devolución del señorío a su linaje $e^{32}$.

En los años que siguieron, por su parte, nuevos servicios prestados ala monarquía en la lucha contra los nobles rebeldes permitieron a Juan Alfonso de Haro ampliar notablemente su patrimonio señorial en la Rioja, aunque la mayor parte de sus adquisiciones resultaron efimeras porque cuando Fernando IV alcanzó la mayorf́a de edad consiguió que muchos de los lugares cedidos fuesen reintegrados al realengo.

En concreto su primer gran servicio a la causa de Marfa de Molina y de su hijo, estuvo representado por la conquista de la ciudad de Nájera en 1297, después de que había sido tomada por un ejército de aragoneses y navarros que actuaba en nombre de Alfonso de la $\mathrm{Cerda}^{33}$. Gracias a este éxito militar la región de la Rioja, de gran valor estratégico, no se perdió para la causa de la monarquia, pero en los meses siguientes continuó estando seriamente amenazada desde los vecinos reinos de Aragón y Navarra, donde algunos nobles rebeldes castellanos desplegaron una intensa actividad en busca de apoyos.

Entre ellos habría que destacar a Juan Núñez de Lara quien, en 1299, después de haberse entrevistado con el rey de Francia, invadió el reino de Castilla por la Rioja al frente de un ejército compuesto en su mayoría por navarros y castellanos. Entonces de nuevo correspondio a Juan Alfonso de Haro defender la causa de la monarquia en tan peligrosa coyuntura, uanque diversos indicios revelan que en su actuación él estuvo ante todo movido por el afán de asegurar su posición política en la región y en

\footnotetext{
${ }^{31}$ Según la Crónica de Femando IV, habiendo sido convocado Juan Alfonso de Haro por la reina María de Molina para que acudiese a Valladolid en 1296, este no quiso acudir "fasta que le entregasen los Cameros que decía que los avía de aver de derecho". Vid. Crónica del Rey Don Fermando Cuarto, "Biblioteca de Autores Españoles", Madrid, 1953, p. 103. Esta noticia nos plantea uno de los interrogantes más difíciles de resolver a la hora de reconstruir el proceso de transferencia del señorio de Cameros de manos del linaje de los Fortuniones, extinguido en 1277, al de los Haro.

${ }^{32}$ Vid. Crónica del Rey Don Femando Cuarto, p. 102.

${ }^{33}$ Ibid. p. 108.
} 
la medida de lo posible incrementar su poderío, exigiendo a la regente el premio por los servicios prestados ${ }^{34}$.

Sin duda alguna el triunfo militar de Juan Alfonso de Haro sobre Juan Núñez de Lara fue posible porque el primero luchaba en territorio sometido a su autoridad política, no sólo porque en él se concentraban la mayor parte de sus señoríos sino también porque la monarquia le habra colocado al frente de las principales fortalezas. Por consiguiente, su capacidad de reclutamiento en aquel entorno era notable, según sugiere la Crónica al indicar que "mando apellidar toda la tierra" cuando conocio la noticia de la invasión, y probablemente ahr radicó el factor decisivo de su triunfo, que le permitio apoderarse de la persona de Juan Núñez de Lara y tenerle preso durante un tiempo en su castillo de Nalda, mientras negociaba con la monarquía el "precio" de la entrega de tan valioso rehén ${ }^{35}$.

La propia reina regente tuvo que acudir a Santo Domingo de la Calzada a negociar directamente con Jusan Alfonso de Haro la entrega de Juan Núñez de Lara, después de que el primero se hubiese negado en Soria a entregárselo al infante Enrique, y el precio que accedio a pagar para apoderarse del prisionero fue muy alto. En concreto se sabe que el señor de Cameros solicitó para si y para su vasallo Gonzalo Alfonso de Quintana algunos lugares de señorí, que les fueron concedidos por juro de heredad, al tiempo que a su hijo Juan Alfonso y a su yerno Felipe de Castro se les tuvo que entregar en dinero la elevada cantidad de $700.000 \mathrm{mrs}^{36}$.

Lamentablemente la Crónica, que nos informa sobre estos pormenores de las negociaciones de la entrega de Juan Núñez de Lara, no precisa cuáles fueron los lugares que tanto Juan Alfonso de Haro como su vasallo Gonzalo Alfonso de Quintana adquirieron por juro de heredad aquel año de 1299. De hecho sobre este último individuo sólo sabemos que fue mayordomo de Juan Alfonso de Haro, que descendía de linaje de caballeros sorianos y que, según consta por el Libro Becerro de las Behetrfas, tenía diversas propiedades en merindades castellanas alejadas del ámbito de Soria

\footnotetext{
${ }^{34}$ Ibid. p. 115.

${ }^{35}$ Bbid. pp. 115-116.

${ }^{36}$ Ibid: p. 116.
} 
y la Rioja, que tal vez pudo obtener gracias a sus servicios a Juan Alfonso de $\mathrm{Haro}^{37}$.

Por su parte, la identidad de algunos de los lugares que presumiblemente adquiriría este último en 1299 resulta posible aventurarla a través de procedimientos indirectos. $Y$ en todos los casos se advierte que concentró preferentemente sus ambiciones en el ámbito del obispado de Calahorra, tanto en su sector serrano, como en las tierras llanas próximas al Ebro. Al primer sector pertenecía la villa de San Pedro de Yanguas, que tenía asignado un territorio jurisdiccional relativamente extenso en comparacion con lo que era habitual en el ámbito camerano-riojano ${ }^{38}$, y que fue concedida a Juan Alfonso de Haro para reintegrarse tras su muerte en el realengo, a pesar de que sus sucesores la reclamasen a Fernando IV como parte de su herencia ${ }^{39}$.

En este mismo sector serrano se localizaba la villa de Yanguas, cabecera también de un extenso territorio jurisdiccional, la cual, habiendo disfrutado de la condición de lugar de behetria, siempre habra elegido no obstante a sus señores entre los titulares del señorío de Cameros del linaje de los Fortuniones ${ }^{40}$. Algunos indicios apuntan, sin embargo, a concluir que Juan Alfonso de Haro no obtuvo el señorío efectivo sobre esta villa de behetría al tiempo qeu se le traspasó el señorio de Cameros confiscado tras la muerte de Simón Ruiz sinoque, por el contrario, durante cierto tiempo su posición de poder en la misma derivó del hecho de que formaba parte

\footnotetext{
${ }^{37}$ Vid. G. MARTtNeZ DIEZ (Ed.) Libro Becerro de las Behetrlas de Castilla, León, 1983, 3 vols. La noticia de que Gonzalo Alfonso de Quintuna fue mayordomo de Juan Alfonso de Haro, en un documento de donación efectuada por el primero al monasterio de Oña, fechada en 1283 en Murillo de Calahorra. Publica I. OCEJA GONZALO, Docuinentación del monasterio de San Salvador de Oña (1032-1284), Burgos, 1983, doc. $n^{0} .242$. Contiene un pequeño error en la identificación de la data tópica.

${ }^{38}$ Sobre la extensión geográfica de esta comunidad de villa y Tierra proporciona datos G. MARTINEZ DíEZ en Las comunidades de villa y Tierra de la Extremadura castellana, Madrid, 1983.

${ }^{39}$ En 1307 Reınón Falque, señor de Cardona, casado con Mari Álvarez, hija de Juan Alfonso de Haro, pedió al rey Femando IV que le diese por el derecho que le correspondia a su mujer la villa de San Pedro de Yanguas (actual San Pedro Manrique) "que debía ser suya e le copiera en partición de parte de su padre Don Juan Alfonso, a quien él la oviera dado por heredad". La petición no fue atendida y la villa penmaneció en el realengo, probablemente hasta que fue cedida a los Manrique en tiempos de Juan I. Vid. Crónica del Rey Don Femando Cuarto, p. 149.

${ }^{40}$ Aunque se trata de una obra sumamente confusa, proporciona datos de interés sobre la historia de Yanguas medieval $\mathbf{M}^{\circ}$. C. DELGADO MARTINEZ, Apuntes sobre la vida rural de la villa y Tierra de Yanguas (Soria). Siglos XII-XVI, Almazán, 1981.
} 
del conjunto de lugares que la monarquía le había cedido "por tierra" en los ámbitos de Soria y Rioja. Más tarde, sin embargo, parece seguro que Yanguas paso a formar parte del patrimonio señorial de Juan Alfonso de Haro I y, tras su muerte, del de su primogénito homónimo, por lo que bien pudo contarse entre los lugares cedidos por la reina regente en $1299^{41}$.

Y por fin también es probable que entre estos figurase la villa de Navarrete, de la que consta que Fernando IV hizo merced a Juan Alfonso de Haro para luego reintegrarla al realengo en $1312^{42}$.

Evidentemente son muchas las lagunas existentes en nuestros conocimientos sobre la vida política de la Rioja durante la minoría de Fernando IV y, por consiguiente, no podemos determinar el alcance del fortalecimiento político de Juan Alfonso de Haro en dicha región en tan críticos años de la historia castellana. Con toda probabilidad, además de los lugares mencionados, éste obtendría algunos otros más en recompensa por los servicios prestados a María de Molina, pero al mismo tiempo, es bastante probable que tratase de incrementar su poder personal continuando con las políticas de usurpación de las que ya había hecho gala en reinados anteriores y que, durante los años de minoría de Fernando IV, serían benévolamente toleradas por la monarquía para evitar que el señor de Cameros cambiase de bando político.

La documentación conservada no resulta, sin embargo, muy pródiga en ofrecer noticias relativas a abusos perpetrados por Juan Alfonso de Haro I y encaminados a reforzar su posición de prepotencia política en las tierras de Rioja y Soria, pero al menos algunas ofrece, si bien no suficientes como para probar que en esta época se vivió una situación de conflictividad semejante a la que caracterizó a los años de la minoría de Alfonso XI.

De hecho sólo tenemos noticias de la existencia de conflictos con un concejo de realengo, el de Ágreda, localizado más allá de las sierras

\footnotetext{
${ }^{41}$ La pertenencia de Yanguas al señorío de Juan Alfonso de Haro II queda puesta de manifiesto en el privilegio otorgado por Enrique II en Burgos 8-IV-1366 a Juan Ramírez de Arellano, concediéndole el señorio sobre todos los lugares que habían pertenecido a Juan Alfonso de Haro y sus hermanos, entre los que figuraba en primer lugar Yanguas y sus aldeas. Vid. nuestro artículo Implantación teritiorial, pp. 68-73.

${ }^{42}$ Vid. el privilegio de Femando IV de 12-III-1312 concedido a Navarrete, por el que revocaba la donación que de la villa había efectuado en favor de Juan Alfonso de Haro, señor de los Cameros, en A. BEnAvidis, Meinorias del Rey Don Fernando IV de Castilla, II, Madrid, 1860, pp. 830-1.
} 
cameranas como punta de lanza de la Extremadura soriana dirigida hacia los reinos de Aragón y Navarra. Por consiguiente el valor estratégico de la villa era notable, y su vinculación con los Haro de Cameros se remontaba al menos a tiempos de Sancho IV, quien llegó a confiar su tortaleza a Juan Alfonso de Haro I y a entregarle en concepto de tierra algunos de los derechos que allı le correspondían. Éste, sin embargo, abusando de la confianza depositada por el rey en él o quizás aprovechando alguna merced de señoróo jurisdiccional sobre la villa y Tierra arrancada en momentos de máxima debilidad del poder regio, trató de ampliar sus atribuciones sobre este concejo de realengo presumiblemente para reconvertirlo en territorio señorial vinculado por juro de heredad a su linaje. $Y$ ası lo confirman las noticias sobre un cerco de Agreda que debió tener lugar an algún momento de la minoría de Fernando IV $^{43}$, y un documento del año 1300 otorgado por Juan Alfonso de Haro I en favor de esta misma villa por virtud del cual daba a ésta por libre de los derechos y pretensiones que contra ella tenia ${ }^{44}$.

A la luz de estas noticias resulta, por consiguiente, posible plantear la hipótesis de que Ágreda figurase entre los bienes cedidos por Maŕ́a de Molina a Juan Alfonso de Haro en 1299 y que este concejo de realengo ocfreciese enconada resistencia a admitir su transferencia a régimen señorial, como consta que lo hizo en sucesivas ocasiones a lo largo de los siglos $\mathrm{XIV}$ y $\mathrm{XV}^{45}$.

\footnotetext{
${ }^{43}$ En 1334 la villa de Ágreda solicitó a Alfonso XI que le devolviese su aldea de Ólvega en enmienda y satisfucción por los daños y males que había sufrido por causa de Don Juan Alfonso de Haro (Se refiere aquí al segundo señor de Cameros de este nombre que acababa de ser ajusticiado por el rey) y de su padre "al ticmpo que tuvieron cercada la dicha nuestra villa e despues cuando nos erainos de pequenna edad e estuvamos en Valladolid". Vid. Archivo municipal de Ágreda, privilegio de Alfonso Xl fechado en Burgos, 16-VIII-1334. Considerando que, para 1307, Juan Alfonso de Haro padre ya había fallecido (Cf. nota 39), hay que presumir que el cerco de Ágreda tendría lugar durante los años de minoría de Fermando IV.

${ }^{4}$ Noticia de este documento en Archivo municipal de Ágreda, inventario de documentos del año 1585 (Hay copia en AHN, Microfilm, rollo 748). Por error en el referido inventario figura la fecha de 1338, porque los redactores no supieron distinguir entre documentos datados por la era hispánica y por el año de la natividad. La fecha de 1338 no se puede admitir porque para entonces cstaban muertos tanto Juan Alfonso de Haro padre como hijo.

${ }^{45}$ Hay que destacar la resistencia en 1395 a ser entregada al mayordomo Juan Hurtado de Mendoza, a quien la había concedido Enrique III, y otras sucesivas resistencias que tuvieron lugar durante el rcinado de Enrique IV, que en variasa ocasiones concedió la villa y Tierra a distintos representantes de la alta nobleza, de los cuales el que más empeño puso en conquistarla fue el duque de Medinaceli. En ningún caso la villa llegó a ser dominada por quienes pretendían convertirse en sus señores con consentimiento de la monarquía.
} 
Por lo demás las relaciones mantenidas por Juan Alfonso de Haro con el resto de concejos de realengo de la región nos resultan muy mal conocidas, aunque diversos indicios permiten presumir que su capacidad de intervención en los mismos fue notable. Y así lo sugieren, por ejemplo, las noticias referentes a la presencia de Juan Alfonso de Haro en Soria o Santo Domingo de la Calzada, y los escasos datos disponibles sobre la identidad de los miembros de su clientela, que confirman su vinculación con vecinos de Soria y Agreda ${ }^{46}$.

Sobre sus relaciones con el concejo de Logroño sabemos ciertamente muy poco, y ni siquiera hemos podido llegar a determinar si figuro entre los lugares en los que llevaba derechos correspondientes a la fiscalidad regia ${ }^{47}$, aunque al menos si nos consta que en tiempos de Sancho IV debieron llegar a producirse enfrentamientos entre ambas partes, cuando el concejo logroñés se apoderó del castillo de Clavijo, que retenfa Juan Alfonso de $\mathrm{Haro}^{48}$. En cualquier caso, sin embargo, de momento no hemos encontrado suficientes indicios documentales para probar que las relaciones entre este señor de Cameros y Logroño fueron durante la minorfa de Fernando IV tan conflictivas y tumultuosas como las de su hijo homónimo con este mismo concejo durante la minoría de Alfonso XI.

De hecho la creación de una Hermandad en 1296, en la que participaron las principales ciudades y villas riojanas y alavesas, pone de manifiesto que los concejos de realengo de la región advirtieron una seria amenaza para su independencia política, y para la propia seguridad de sus vecinos, en la actitud de los miembros de la alta nobleza de la región ${ }^{49}$. A pesar de ello, sin embargo, las noticias documentales disponibles apenas

\footnotetext{
${ }^{46}$ Las noticias sobre sus estancias en Soria y Santo Domingo de la Calzada las proporciona la ya referida Crónica. Ya adelantamos cómo uno de los más destacados vasallos de Juan Alfonso de Haro, Gonzalo Alfonso de Quintana, descendía de Soria. Por otra parte también se dispone de referencias aisladas que indican que reclutó a alguno de sus criados en Ágreda. Así, en abril de 1344, aparece dictando una sentencia un tal M. Peres, que es identificado como "çevador que fue de Don Juan Alfonso de Haro". En protocolos notariales del Archivo municipal de Ágreda.

${ }^{47}$ En el doc. cit. en nota 28, no se menciona al concejo de Logroño entre los lugares en los que Juan Alfonso de Haro cobraba los derechos del rey; pero esto es lógico dado que se otorga a petición del propio concejo logroñés. No hay que excluir, por lo tanto, que también Logroño figurase entre los lugares que este noble tenía "en tierra" por el rey.

${ }^{48} \mathrm{Cf}$. nota 27.

${ }^{49}$ Vid. C. GONZÁLEZ MINGUEZ, Alava en el tránsito del siglo XIII al XIV. Antecedentes de la crisis bajomedieval, en "La fonnación de Alava", Vitoria, 1986, p. 216.
} 
ilustran casos de abusos nobiliarios perpetrados en la región riojana en los cinco últimos años del siglo XIII; y por lo que respecta a Juan Alfonso de Haro, que fue durante estos años quien controlo los principales resortes del poder en la región, sólo en el caso de Agreda nos lo encontramos implicado en un episodio de abierto enfrentameinto con un concejo de realengo.

Por contraste, las noticias referentes a denuncias de la actitud violenta de su hijo Juan Alfonso de Haro II durante los años de la minoría de Alfonso XI son bastante numerosas $y$, aunque este hecho puede obedecer a una simple casualidad en la conservación de la documentación, es también probable que constituya el reflejo de una realidad histórica más marcada por el signo de la conflictividad y la violencia. Por consiguiente, y aunque somos conscientes del riesgo que conlleva proponer conclusiones generalizadoras a partir de insuficientes pruebas empiricas, nos atreverfamos a aventurar la hipótesis de que la posición política de Juan Alfonso de Haro en la Rioja, durante la minoría de Fernando IV, estuvo caracterizada por un incremento progresivo de su poderío, alcanzado gracias a sus éxitos militares, adecuadamente compensados por la monarquía mediante cesiones de señoríos, y también por el logro de una cierta primacía frente a otras instancias regionales de ejercicio del poder con las que mantendría unas relaciones marcadas más por el consenso que por la violencia cruenta.

Una vez, sin embargo, que la monarquía superó las principales dificultades que la amenazaron durante los primeros años del reinado de Fernando IV, la posición de prepotencia de Juan Alfonso de Haro en la Rioja debio remitir, y as lo prueba el hecho de que varios de los lugares que le habran sido cedidos en señorío se reincorporaron al realengo en los primeros años del siglo XIV. Dado, no obstante, que desconocemos la fecha precisa en tuvo lugar la muerte de éste, no podemos determinar si ya en sus últimos años de vida se hicieron efectivas las primeras revocaciones de mercedes o si, por el contrario, Fernando IV esperó a su fallecimiento para recuperar los lugares que su madre habla tenido que ceder al señor de Cameros para salvar su trono. No obstante, la firme actitud de este monarca pone de manifiesto hasta qué punto la institución que él encarnaba estaba decidida a resistir las presiones nobiliarias e impedir as la reducción del realengo, puesto que reincorporaciones como las que él decreto y que afectaron a los Haro de Cameros, que le hablan sido fieles durante los conflictos de su minorfa, no se vuelven a constatar en la historia castellana a partir del acceso al trono de Enrique de Trastamara, ni siquiera durante el reinado de los Reyes Católicos. 


\section{Las "malfetrías" de Juan Alfonso de Haro II en la Rioja DURANTE LA MINORÍA DE ALFONSO XI}

Sin entrar a determinar la adscripción de Juan Alfonso de Haro a los bandos nobiliarios que se disputaron el control de la persona del rey y de las instituciones centrales de la monarquía durante los años de minoría de Alfonso XI, un notable contraste que advertimos en su posición con respecto a la de su padre durante los años de minoría de Fernando IV radica en que se vio implicado en numerosos conflictos de marcado carácter violento de forma que, aunque su autoridad en la Rioja alcanzo elevadas cotas de efectividad, frecuentemente se impuso por la violencia y por esta razón la resistencia ofrecida por otras instancias de poder, entre las que destacó por su dinamismo el concejo de Logroño, fue mucho más intensa.

Según atestiguan los escasos documentos conservados, los años que siguieron a la muerte de Fernando IV fueron catastroficos para la Rioja, porque miembros de la nobleza de muy distinto rango, convertidos en auténticos "malhechores feudales", sometieron a la población campesina a todo género de abusos, provocando en algunos casos la despoblación de ciertos lugares, y en otros obligando a pequeños núcleos de población a la construcción de cercas y otros edificios fortificados que garantizasen su defensa ${ }^{\text {so }}$. Frecuentemente los actos más vandálicos serían obra de representantes de la pequeña nobleza, a los que los documentos llaman "hombres baldros", que hablan convertido el saqueo en su modo de vida. Pero no cabe duda de que estos hombres encontraron el caldo de cultivo propicio para sus actividades devastadoras en la inestabilidad política generada por la actitud beligerante de los principales representantes de la alta nobleza

\footnotetext{
${ }^{50}$ El lugar riojano de Santa Coloma, próximo a la frontera de Navarra, tuvo que construir una cerca durante el reinado de Alfonso XI para defenderse do los ataques y robos perpetrados por miembros de la nobleza, que amenazaban con llevarle a la despoblación. Se hace constar en privilegio de Alfonso XI fechado en Toledo, 4-XII-1338 en AHN, Códice 106-B, fol. 214. También AHN, Clero, carp. 1033, $\mathrm{n}^{\circ}$. 15. Un caso semejante es el de los cuatro lugares del señorío de San Millán de la Cogolla que fucron agrupados por decisión del abad en el lugar de Badarán, que para garantizar su defensa fue dotado con una cerca. Alfonso XI autorizó este proyecto por privilegio del año 1326. Vid. AHN, Clero, leg. 3065. Las referencias documentales a probleinas de despoblación que amenazaron a otros muchos lugares riojanos en esta Época son numerosas. Por cjemplo, para cl caso de Bezares, vid. privilegio de Alfonso XI fechado en Burgos 13-VI-13i5 en AHN, Clero, carp. 1033, no. 2. Para Ribafrecha privilegio de Alfonso XI de Toro, 20-IV-1316 en AHN, Códice 106-B, fol. 125, y otro privilegio de este mismo monarca dado en Toro en mayo de ese mismo año. lbid. fol. 129.
} 
que se habran fijado como objetivo incrementar su poderío político a toda costa.

Y, por consiguiente, estos últimos eran los auténticos responsables del desencadenamiento de la violencia nobiliaria, que en la Rioja entendemos que alcanzó mayor difusión e intensidad durante la minoría de Alfonso XI que en momentos anteriores del siglo XIII caracterizados en el conjunto del reino de de Castilla por la inestabilidad política.

Sin duda alguna el principal representante de los ricos hombres castellanos en la Rioja durante esos años fue Juan Alfonso de Haro II, y de hecho en la mayor parte de la documentación que hemos consultado las denuncias de monasterios y concejos sobre abusos nobiliarios perpetrados en la región durante los años de minoría de Alfonso XI le presentan a él o a hombres de su clientela como principales responsables de los mismos. No obstante, en aras a la precisión, hay que hacer constar que también otros poderosos nobles castellanos, que a diferencia de Juan Alfonso de Haro no tenían centrados sus intereses políticos en la región riojana, fueron denunciados como autores de agravios, destacando a este respecto por ejemplo el caso del infante Felipe, uno de los tutores del rey, acusado por el concejo de Logroño en $1323^{51}$. A su vez otros nobles de rango inferior al de los ricoshombres también desarrollaron durante la minoría de edad de Alfonso XI una cierta actividad política orientada a incrementar su poderío en la región riojana, entrando a veces incluso en conflicto con el propio Juan Alfonso de Haro. Y éste parece que pudo ser el caso de Juan Martínez de Leiva, alférez del infante Don Pedro, quien presumiblemente en 1315 estaba apoderado del señorío emilianense de Ventosa, sobre el que habran centrado sus ambiciones Juan Alfonso de Haro y sus hijos en los años inmediatamente anteriores ${ }^{52}$.

No obstante, los datos disponibles sobre la actividad política en el ámbito regional riojano de estos nobles de inferior rango son escasos y apenas permiten reconstruir un panorama mínimamente preciso, por lo que aqui no vamos a ocuparnos de ellos, para centrarnos en contrapartida en la

\footnotetext{
${ }^{51}$ Referencia a la carta otorgada por el infunte Felipe, tutor del rey, al concejo de Logrono, comprometiéndose a no agraviarle en el futuro, fechado el 4-III-1323 en S. ANDRÉS VALERO y E. IRADIER SANTOS, Documentación medieval del Archivo Municipal de Logrono II), "Brocar", 11 (1985), pp. 11-59, doc. nº. 53.

${ }^{32}$ Aportamos noticias a este respecto en $E l$ intervencionisino, apoyándonos en referencias documentales aportadas por L. SERRANO, Cartulario de San Millán de la Cogolla, Madrid, 1930, p. Cl.
} 
figura de Juan Alfonso de Haro II y de sus parientes más próximos, que fueron los principales protagonistas de la ofensiva nobiliaria en la Rioja en las primeras décadas del siglo XIV.

$\mathrm{La}$ abundancia de noticias sobre abusos cometidos por Juan Alfonso de Haro II contra monasterios y concejos riojanos, y también contra alguno soriano como Ágreda, no debe hacernos olvidar sin embargo que éste habra heredado de su padre un posición que le debra asegurar cierta preeminencia política en la región sin necesidad de acudir al abuso de la violencia. En su caso sin embargo, la documentación apenas ilumina la faceta de su actividad política relacionada con tareas de gobierno y administración desarrolladas por delegación de la autoridad monárquica. De hecho desconocemos si siguió controlando las importantes fortalezas de realengo que se habran encomendado a su padre y si, por virtud de su vinculación vasallática con la monarquía, continuó percibiendo en concepto de tierra ciertos derechos pertenecientes a la fiscalidad regia en los principales concejos de realengo de los ámbitos de Soria y Rioja. Pero al menos sl nos consta que la monarquía le continuó reconociendo formalmente cierta condición de preeminencia política en la región, que se tradujo, por ejemplo, en su nombramiento como prestamero de la merindad de Rioja ${ }^{33}$, y en su permanencia al frente de Calahorra, ciudad en la que habran estado presentes de forma ininterrumpida sus antepasados desde las primeras décadas del siglo XIII ${ }^{54}$.

En sus relaciones con los concejos realengos de la region, Juan Alfonso de Haro II, no obstante, manifestó una actitud que por su elevado grado de hostilidad y violencia no era propia de un representante de la administración territorial de la monarquia, aunque hay que advertir que a

\footnotetext{
${ }^{53}$ Vid. privilegio dado en Toro, 28-IX-1314, por Alfonso XI a la villa de Logroño en que confirma las dos ferias francas de 15 dias que le habian concedido María de Molina y el infante Pedro, su tutores. En esta confirnación ordena a Juan Alfonso de Haro y a cualquier otro que fuese prestamero de la merindad de Logroño, y al Adelantado o Merino Mayor de Castilla que respeten y hagan respetar el privilegio. Copia en RAH, Salazar y Castro, 0-16, fols. 221 y ss. No hemos podido profundizar en la caracterizaicón del oficio de prestamero de la merindad de Logroño. La figura del prestamero también la encontramos en otras merindades riojanas. Por ejemplo, en Rioja y Bureba era prestamero en 1285 Lope Díaz de Haro (Vid. I. RODRIGUEZ R. DE LAMA op. cit. doc. no. 429). En estos casos el rango político de los prestameros era, pues, muy superior al habitual entre los merinos menores.

${ }^{34}$ Cf. nota 29 (Juan Alfonso de Haro II venía siendo tenente de Calahorre desde bastante antes de la muerte de su padre). Revela que continuó ejerciendo influencia sobre el concejo calagurritano, durante el reinado de Alfonso XI, un pergamino del archivo municipal del año 1320 que, según L. DF SAN JUAN DE LA CRUZ, se titula "Carta de amparo del señor de los Cameros". Vid. su Historia de Calahorra y sus glorias, Valencia, 1925, p. 278. No hemos tenido oportunidad de consultar este documento.
} 
este respecto no difirió sustancialmente de la de otros oficiales de esta misma administración, tales como adelantados mayores y merinos, a los cuales tanto los concejos como los monasterios riojanos acusaron de cometer todo tipo de tropelías durante las minorias de Fernando IV y Alfonso $\mathrm{XI}^{55}$. De hecho tanto estos oficiales como Juan Alfonso de Haro vieron en los concejos realengos presas sobre las que había que lanzarse para incrementar su propio poderío político en la región, y circunstancialmente también para obtener ingresos rápidos a través del saqueo.

Pero estos concejos no resultaron ciertamente presas fáciles, sino que en muchos casos ofrecieron una enconada resistencia, con frecuencia coronada con el éxito. Y, para incrementar su capacidad de resistencia, consta que recurrieron al procedimiento ya ensayado en reinados anteriores de confederarse en hermandades. En concreto, tenemos noticias de la existencia de una hermandad de la merindad de Logroño durante los años de minoría de Alfonso $\mathrm{XI}^{\text {s6 }}$, y en otro ámbito en el que también intervino Juan Alfonso de Haro, sabemos de la concertación de numerosas treguas por el concejo de Ágreda con concejos aragoneses y navarros, que iŕan orientadas al fortalecimiento político de este concejo castellano, constantemente amenazado por los señores de Cameros tanto durante la minoría de Fernando IV como durante la de Alfonso $\mathrm{XI}^{57}$.

Lamentablemente no sabemos apenas nada sobre el funcionamiento de la hermandad de la merindad de Logroño, en la que presumiblemente se

\footnotetext{
${ }^{35}$ Denuncias de los abusos cometidos por adelantados y merinos en el concejo de Santo Domingo de la Calzada hasta la mayoría de edad de Alfonso XI, en privilegio concedido por este monarca al concejo en Valladolid, 2-I-1236. Publica C.LOPEZ DE SILANES y E.

SAINZ RIPA, Colección Diplomática Calceatense. Archivo Municipal 1207-1498, Logroño, 1989 , doc. $n^{0}$. 19. Noticias sobre abusos cometidos por adelantados y merinos en un señorío monástico, el de Cirueña, perteneciente a Santa María de Nájera, en documento de 22-IX1387, en AHN, Clero, leg. 2944.

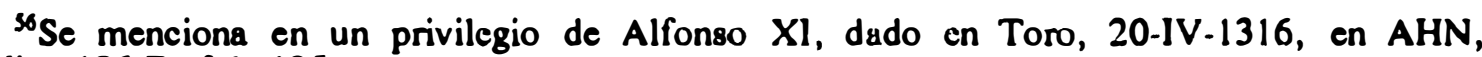
Códice 106-B, fol. 125.

${ }^{57}$ La mayoría de las treguas las concertó el concejo de Agreda durante la minoría de Femando IV. A este periodo corresponden las siguientes: con Corella el 11 de julio de 1302; con los concejos castellanos de Deza, La Alameda y Miñana el 24 de junio de 1303; con el concejo también castellano de Serón el 6 de junio de 1303; con Cintruénigo el 4 de junio de 1304, con Aranda, Calcena, Bijuesca y Verdejo, en Aragón, el 20 de mayo de 1296 y el 14 de octubre de 1302; con el concejo castellano de Almazán el 22 de junio de 1303; y con el aragonés de Calatayud el 6 de octubre de 1302. Durante el reinado de Alfonso XI sólo cabe destacar la tregua firmada con Tudela de Navarra el 24 de diciembre de 1329. Todas las noticias sobre estas treguas, en un inventario de documentos del Archivo municipal de Ágreda del año 1585 (Se puede consultar en AHN, Microfilm, rollo 748).
} 
integrarłan bastantes concejos de señorío monástico, pero en contrapartida si que disponemos de más noticias sobre las actuaciones políticas y militares del propio concejo logroñés, que a la luz de las mismas se nos presenta como una de las instancias políticas que más resistencia ofreció al expansionismo de Juan Alfonso de Haro. En concreto hay que destacar a este respecto su intervención en la conquista de Leza, lugar perteneciente al señorío de Santa María de Najera que había sido tomado a la fuerza por Juan Alfonso de Haro y sus hombres, y desde el cual éstos estaban robando y saqueando toda la región circundante. Como reacción, el concejo de Logroño envió a su milicia para expulsar del lugar a las compañfas del señor de Cameros, y una vez coronada con el éxito su empresa se eligió a Gonzalo Yánez de Baztán para que tuviese Leza en nombre del concejo logroñés. Y en esta situación continuo, a pesar de los ruegos del monasterio de Najera para que se le devolviese su señorfo, hasta que en 1334 ordenó el monarca que se procediese a esta devolución, un año después de haber sido ajusticiado Juan Alfonso de $\mathrm{Haro}^{58}$.

En otros casos el concejo de Logroño consiguió poner freno a las empresas expansionistas, cuando no declaradamente depredadoras, de Juan Alfonso de Haro en el ámbito de la merindad, de la que no debemos olvidar que, paradojicamente, él era prestamero. Y asl, por ejemplo, no pudo impedir que Ribafrecha, lugar también perteneciente a Santa María de Najera, fuese tomada por las compañfas del señor de Cameros, se destruyese su cerca y finalmente fuese toda ella incendiada y destruida ${ }^{59}$.

La secuencia de acontecimientos relacionados con la destrucción de Ribafrecha que permite reconstruir la documentación disponible resulta un tanto contradictoria puesto que, si bien por un lado no hay duda de que fue Juan Alfonso de Haro quien la tomó de su legítimo señor, el monasterio de Nájera, y mandó destruir su cerca ${ }^{60}$, por otro parece que él mismo, aliado con los hombres buenos de la hermandad de la merindad de Logroño, llegó a cercar a su propio hijo Juan y a Juan Fernández de Baztán para poner freno a los abusos que desde sus bases de Ribafrecha ambos estaban come-

\footnotetext{
${ }^{58}$ Vid. la provisión de Alfonso XI, dirigida al concejo de Logroño y fechada en Valladolid, 20-IV-1334, que publica M. CANTERA MONTENEGRO, Santa Maria la Real de Nájera. Siglos XI-XIV, Madrid, 1987, doc. no. 266.

${ }^{39} \mathrm{lbid}$. Coinplementa los datos de esta provisión de Alfonso XI otra del mismo fechada en Toro, 20-IV-1316, en AHN, Códice 106-B, fol. 125.

${ }^{60}$ Ésta es la información que aporta la provisión de 1334 citada en nota 58.
} 
tiendo en la región circundante ${ }^{61}$. No hay que descartar, por consiguiente, la existencia de conflictos internobiliarios que propiciasen una continua fluctuación de las alianzas políticas, pero al mismo tiempo hemos de tener en cuenta también que la versión de los hechos que presentan los documentos puede contener deformaciones que repondan a las circunstancias políticas que rodearon a su otorgamiento. $\mathrm{Y}$ asI nos lo sugiere, circunscribiéndonos al caso de Ribafrecha, el hecho de que sea el documento de 1334 el que presenta un cuadro negativo de las actuaciones de Juan Alfonso de Haro, que hacía un año habia sido ajusticiado por Juan Alfonso de Haro, mientras que en los documentos de 1316 se insiste en presentar a éste como defensor de los intereses de la monarquia, silenciando actuaciones que diff́cilmente se podian presentar como conciliables con éstos. De hecho en estos últimos documentos el propio prior de Nájera aparece actuando "al dictado" de Juan Alfonso de Haro, pero nunca deja entrever que se estén ejerciendo sobre él ningún tipo de presiones, limitándose a reconocer que en sus actuaciones simplemente está atendiendo los "ruegos" del señor de Cameros $^{62}$.

En cualquier caso el establecimiento de una alianza coyuntural entre Juan Alfonso de Haro y la hermandad de la merindad de Logroño hacia 1316 parece fuera de duda $y$, por tanto, presenta problemas de interpreta-

\footnotetext{
${ }^{61}$ Según una provisión de 1316 citada en nota 59. En este documento se hace constar expresamente que la villa de Ribafrecha "fue quemada c los mucbles que avían los que y moraban perdidos e las huertas cortadas et en las vinnas fechos mui grandes dannos por razon que lohan fijo de don Iohan Alffonso e lohan Femandez de Baztan e otras gentes que eran con ellos facían aalgunas cosas que eran danno a la tierra. Et los dichos don lohan Alfonso e los omnes bonos de la hernandat vinieron sobre cllos por complir mio serviçio y cercáronlos en la dicha villa de Rifabrecha do el dicho Iohan Ferrandez avía una casa fuerte".

${ }^{62}$ En este sentido hay que destacar la carta de poblamiento dada por el prior de Nájera, Don Guillén de Monladun, al lugar de Oriemo, pucbla nueva fundada para sentar a los vecinos de Ribafrecha, el 25-III-1316, que fuc conlinnada por Alfonso XI en Toro, en mayo de ese mismo año, en AHN, Códice 106-B, fol. 129. El prior reconoce expresamente que había recibido una carta de Juan Alfonso de Huro en la que le rogaba que se diese a los vecinos de Ribafrecha el lugar de Oriemo, para poblar, y que se les concediesen ciertos privilegios en los primeros años para facilitar el poblamiento. En la provisión de Alfonso XI de 1316 citada en nota 59, el rey, por su parte, reconoce que había recibido cartas de Juan Alfonso de Haro y de la hermandad de la merindad de Logroño solicitándole que confirmase la fundación de la puebla de Oriemo, por el monasterio de Nájera, y concediese a sus pobladores ciertas exenciones de impuestos. No hay duda, por consiguiente, de que fue Juan Alfonso de Haro el principal promotor de esta empresa, aunque resulta difícil determinar qué objetivo perseguía al promoverla. Fue, en cualquicr caso, relativamente frecuente que este noble intercediese ante la monarquía solicitando exenciones o rebajas de impuestos para los vecinos de diversos señoríos monásticos, de los que se erigía en interlocutor en lugar de sus legítimos señores.
} 
ción considerables, ya que entra en contradicción con la actuación por esas mismas fechas del concejo de Logroño en la conquista de Leza.

Futuras investigaciones y nuevos hallazgos documentales tal vez permitan dar respuestas en el futuro a estos interrogante, pero de momento, si sopesamos las informaciones disponibles, debemos inclinarnos a concluir que Juan Alfonso de Haro aprovecho las circunstancias de debilitamiento del poder monárquico durante la minoría de Alfonso XI para ampliar mediante el recurso a la violencia sus bases de ejercicio del poder en la Rioja, a costa de los concejos de realengo y de los monasterios titulares de señoríos de vasallos. La capacidad de resistencia de estos últimos fue escasa y, por consiguiente, la mayoría de ellos no pudieron evitar que el señor de Cameros se apoderase de varios de sus lugares de señorío e incluso impusiese su autoridad sobre los propios monasterios ${ }^{63}$. Pero los concejos de realengo, por el contrario, manifestaron una mayor madurez política y capacidad militar, al contar entre su población con destacados caballeros vinculados a la monarquia por lazos de vasallaje, que eran particularmente poderosos en el concejo de Logroño ${ }^{64}$. $Y$ de hecho consiguieron en varios casos poner freno con éxito a los intentos expansionistas de Juan Alfonso de Haro.

En concreto, además del caso de Logroño que ya hemos analizado en parte, ilustra muy bien este tipo de actuaciones concejiles el caso de la villa soriana de Ágreda, plaza clave para el control de la frontera con Aragón y Navarra, y que quizás por ello venfa siendo objeto preferido de la ambición de los señores de Cameros desde los tiempos de la minoría de Fernando IV. Durante la minoria de Alfonso XI, Juan Alfonso de Haro II continuo con la tradición establecida por su padre, y al parecer con mayor éxito, ya que en 1334 la villa de Ágreda denunció que éste le habra tenido ocupada la aldea de Ólvega y le habra causado muchos males y daños durante los años de minoría del rey, cuando éste estaba en Valladolidos.

\footnotetext{
${ }^{63}$ Trataunos por extenso esta cuestión en $E l$ intervencionismo.

${ }^{4}$ Entre otros, podríamos destacar a Gonzalo Yáñez de Baztán, vasallo del rey a quien el concejo de Logroño encomendó la guarda de Leza, tras haberla conquistado de Juan Alfonso de Haro. Cf. nota 58. También destaca como individuo poderoso Rodrigo Alfón de Logroño, vasallo y lugarteniente de ballestero mayor de Alfonso XI, a quien después del ajusticiamiento de Juan Alfonso de Haro el rey hizo mereed de los pecheros de Agoncillo y Daroca, antiguos señonios del señor de Cameros y de su esposa Teresa de Almoravit. El privilegio de Alfonso $\mathrm{XI}$ en confirmación de Juan I en AGS, EMR, Mencedes y Privilegios, leg. 80, fol. 45.

${ }^{65} \mathrm{Cf}$. nota 43.
} 
El hecho de que esta villa soriana esperase a la muerte por ajusticiamiento de Juan Alfonso de Haro para reclamar su antigua aldea demuestra que, hasta cierto punto, su posición política sufrió un cierto deterioro con ocasión de sus enfrentamientos con los señores de Cameros durante la minoría de Alfonso XI, y que la toma de las riendas del poder por parte del rey no contribuyó en principio de forma apreciable a reforzarla, como habrfa cabido esperar teniendo en cuenta que se trataba de un concejo de realengo de elevado valor estratégico y muy amenazado por el afán expansionista de la alta nobleza. No obstante, a pesar de las pérdidas sufridas por Ágreda, no puede afirmarse que Juan Alfonso de Haro resultase plenamente triunfante en el conflicto sostenido con la villa, y asi lo confirma el que en septiembre de 1322 firmase una carta de tregua con el concejo agredeño garantizándole que en el futuro no haría guerra contra él ni le causarfa daño por razón de los pleitos y diferencias que entre si tenfan ${ }^{66}$.

Presumiblemente también tendría este mismo sentido la carta de amparo que, al parecer, concedió a Calahorra en el año 1320; pero, dado que no hemos podido profundizar en la caracterización de las relaciones políticas mantenidas entre ambas partes durante la minoría de Alfonso XI no resulta prudente ir más allá en el establecimiento de paralelismos. Por lo demás tampoco disponemos de noticias que nos informen sobre las relacines mantenidas por Juan Alfonso de Haro con los otros grandes concejos de realengo de la región, tales como Alfaro, Santo Domingo de la Calzada, Nájera e incluso la propia Soria. Muy probablemente su interés en intervenir en los ámbitos de influencia de varios de estos concejos fue escasa, y asi parece confirmarlo para el caso de Santo Domingo de la Calzada, cabecera de la merindad de Rioja, el hecho de que en las denuncias presentadas sobre abusos cometidos contra esta ciudad porla nobleza durante la minoría de Alfonso XI nunca se haga referencia expresa al señor de Cameros y si, sin embargo, a los adelantados mayores de Castilla y a sus merinos en Rioja $^{67}$. En Soria también parece bastante improbable que tratase de intervenir, aunque la carencia prácticamente total de fuentes documentales para esta ciudad en la época de Alfonso XI no permite aventurar ninguna afir-

\footnotetext{
${ }^{66}$ Noticia sobre esta carta de tregua fechada el 15 de septiembre de 1322 , en el inventario de documentos citado en nota 57.

${ }^{67} \mathrm{Cf}$. nota 55.
} 
mación en este sentido. La posición de Nájera pudo, en cierta medida, llegar a ser similar a la de Logroño, e incluso se puede presumir que el concejo corriese la misma suerte que el monasterio de Santa María la Real, entrando en una relación de dependencia respecto al señor de Cameros. Y, por fin, la de Alfaro pudo guardar cierta similitud con la de Agreda, teniendo en cuenta que también era una plaza con notable valor estratégico en la que los Haro de Cameros habían controlado un tiempo la fortaleza. Pero, en tanto no se exploren nuevos fondos documentales, todas estas hipótesis no dejarán de constituir simples resultados de ejercicios dialécticos, inadecuados para dar cuenta de la realidad histórica.

\section{Ajusticiamiento de Juan alfonso de Haro Y POSTERIOR TRAYECTORIA DE SU LINAJE EN RIOJA Y CAMEROS}

Durante los primeros años de gobierno personal de Alfonso XI, la posición política de Juan Alfonso de Haro no sufrió ninguna merma considerable, y asf lo confirma el que se le siguiesen asignando puestos preeminentes en las ceremonias cortesanas junto a sus hermanos ${ }^{68}$. No obstante, pronto el monarca comenzo a advertir el talante rebelde y conspirador del señor de Cameros, llegando a sospechar en diversas ocasiones que actuaba en connivencia con Don Juan Manuel y con el señor de Vizcaya, Don Juan Núñez de Lara, "para deservir al rey"69. Y, teniendo en cuenta estos precedentes, no debió por consiguiente provocar notable sorpresa la decisión tomada por Alfonso XI en 1333 de ordenar prenderle y darle muerte en su propio castillo de Agoncillo, porque según la Crónica se le habría encontrado culpable de desviar el dinero recaudado en nombre del rey para la financiación del cerco de Gibraltar hacia una campaña de saqueo y de promoción de una rebelión contra la monarquía, en la que trató de implicar a Don

\footnotetext{
${ }^{68}$ En las ceremonias de coronación de Alfonso XI y en las que siguieron, cuando este monarca anmó caballeros a los niembros más destacados de la sociedad política castellana, aparece ocupando un lugar destacado Juan Alfonso de Haro y también su hermano, Álvar Díaz de Haro. Vid. Crónica del rey don Alfonso el Onceno en "BAE", LXVI, Madrid, 1953, cap. CI. 263.

${ }^{69}$ Varias referencias al respecto en la citada crónica de Alfonso XI, pp. 237-238 y 262 -
} 
Juan Manuel, Don Juan Núñez de Lara, Don Gonzalo de Aguilar y al propio gobernador de Navarra ${ }^{70}$.

Las repercusiones de esta decisión regia fueron inmediatas en la vida política regional del ámbito riojano y soriano en el que estamos centrando nuestra atención, y así lo prueba, por ejemplo, la coincidencia de solicitudes al monarca para que devolviese a sus legitimos titulares algunos de los señoríos que en su tiempo habian sido ocupados por Juan Alfonso de Haro, como es el caso de Ólvega, aldea solicitada por el concejo de Ágreda, y Leza, lugar reclamado por el monasterio de Nájera al concejo de Logroño, que lo había arrebatado a las compañlas del señor de Cameros y no lo habia reintegrado a su legitimo señor, presumiblemente alegando razones de seguridad. En ambos casos en 1334 el monarca, atendiendo las solicitudes presentadas, dispuso la devolución de los lugares a sus antiguos señores, y ello demuestra hasta qué punto la desaparición de Juan Alfonso de Haro representó una condición necesaria para que las instancias que más habían sufrido los efectos de la expansión nobiliaria acelerada durante la minoría de Alfonso XI, y que fueron concejos realengos y monasterios, recuperaran en el ámbito riojano parte de las posiciones perdidas ${ }^{71}$.

Sobre la suerte de los señoríos que pertenecían a Juan Alfonso de Haro en el momento de su muerte, las noticias disponibles resultan algo confusas, ya que si bien la Crónica en un lugar afirma que, tras mandar ajusticiar a Juan Alfonso de Haro, el rey entrego el señorío de los Cameros a sus hermanos Álvar Díaz y Alfonso Téllez de Haro, y tomó para sí todas las demás villas, lugares y castillos que aquél había tenido en vida ${ }^{72}$, en otro lugar señala que Alfonso Téllez de Haro llegó a enviar una carta al rey en la que le comunicaba que no quería seguir siendo su vasallo, despidiendose y desnaturándose de él "porque decía que le tenía tomada la heredat de Don Juan Alfonso su hermano"73.

En cualquier caso, lo cierto es que los hermanos de Juan Alfonso de Haro continuaron ocupando una posición política destacada en la Rioja en los años que siguieron al ajusticiamiento de éste, y desafiando desde los Cameros la autoridad del rey, quien en 1334 tuvo que recurrir a solicitar la

\footnotetext{
${ }^{70}$ lbid. p. 263.

"Cf. notas 43 y 58.

${ }^{72}$ Crónica del rey don Alfonso, p. 263.

${ }^{73}$ Jbid. p. 277.
} 
ayuda militar de los concejos de Soria, Yanguas y otros de la comarca para que acudiesen a cercar el castillo de Soto de Cameros, desde el que Alfonso Téllez estaba robando y haciendo mal en toda la tierra circundante. Y asf lo hicieron, manteniendo cercada la referida fortaleza durante todo el tiempo que el rey estuvo cercando al señor de Vizcaya en Lerma, probablemente para evitar que Alfonso Téllez de Haro acudiese en auxilio de este último ${ }^{74}$

Antes de seguir trazando la trayectoria política de estos hermanos de Juan Alfonso de Haro, hay que hacer constar no obstante que varios de los señoríos que hablan pertenecido a éste no pasaron a su poder sino que fueron directamente confiscados por el rey. $Y$ asi consta que ocurrio, entre otros casos, con las Cinco Villas y Valdecanales ${ }^{75}$, Yanguas ${ }^{76}$, Agonci$10^{77}$ y Murillo de Calahorra ${ }^{78}$. La viuda de Juan Alfonso de Haro, Teresa de Almoravit, por su parte siguió siendo señora de algunos pequeños lugares que debran pertenecer al patrimonio de sus antepasados, tales como Daroca y Sotes, aunque muy pronto optó por vender sus derechos a Rodrigo Alfón de Logroño, que adquirió Daroca, y al concejo de Navarrete, que

\footnotetext{
${ }^{74}$ Ibid. p. 277. En p. 272 también denuncia la crónica que Alfonso Téllez de Haro se había aliado con Don Juan Manuel, Don Juan Núñez de Lara y Don Gonzalo de Aguilar en deservicio del rey.

${ }^{73}$ En el libro becerro de las behetrias todos estos lugares aparecen identificados como pertenecientes al rey, con la excepción de Viniegra de Suso, que se indica que pertenecía a Juan Alfonso Carrillo. Vid. G. MART1NEZ DIEZ, Libro Becerro, pp. 617-20.

${ }^{16} \mathrm{El}$ hecho de que, en 1334, Alfonso $\mathrm{Xl}$ ordenase al concejo de Yanguas que acudiese con tropas para colaborar en el cerco de Alfonso Yánez de Haro, en la fortaleza de Soto de Cameros, sugiere que entonces esta villa no pertenecía al señorio de este último. Cf. nota 74. No obstante, cuando Enrique Il transfirió a Juan Ramírez de Arellano el título de señor de Cameros y todos los señoríos que habían pertenecido a Juan Alfonso de Haro y sus hermanos, incluyó en primer lugar la villa de Yanguas y su Tierra. Vid. nuestro artículo Implantación territorial.

${ }^{77}$ En 1336 Alfonso XI hizo menced de Agoncillo a su ballestero mayor, Sancho Sánchez de Rojas. Repasa la trayectoria de este señorio I. CADIÑANOS BARDECI, en Agoncillo y su fortale$2 a$, "Brocar", 16 (1990), pp. 61-70.

"Tras el ajusticiamiento de Juan Alfonso de Haro, Alfonso XI hizo merced de Murillo de Calahorra a Femán Ruiz de Guona. Vid. I.RODRlGUEZ R. DE LAMA, op. cit. doc. $n^{0}$. 552. Vid. también, sobre cl origen de este señorio, nuestro artículo Un monasterio cisterciense, pp. 131-132.
} 
adquirió los vasallos y botejeros, casas, solares y heredades que le perteneclan en Sotes ${ }^{79}$.

No cabe duda, por consiguiente, que con la muerte violenta de Juan Alfonso de Haro en 1333 se desencadenó un proceso de fragmentación del patrimonio señorial que éste había logrado reunir, que favoreció en cierto modo el debilitamiento de la posición política de la alta nobleza en la región, a pesar de que en un principio las actuaciones de los nuevos señores de Cameros parecian sugerir que la región todavía representaba un peligroso reducto de oposición nobiliaria a la monarquía.

Lamentablemente, no hemos podido determinar con precisión qué desenlace tuvieron los episodios de rebeldía de Alfonso Téllez de Haro después del cerco de Soto, pero parece seguro que se dio una reconciliación tanto de él como de su hermano Álvar Díaz de Haro con Alfonso XI, ya que éste les hizo merced por juro de heredad a ambos de la villa de Nieva, situada en la merindad de Logroño ${ }^{80}$.

Pero a pesar de que la actitud de la monarquia hacia estos señores de Cameros no parece que fuese represora, sino más bien al contrario, es indudable que su posición política y la de sus sucesores se fue deteriorando progresivamente durante los reinados de Alfonso XI y Pedro I, entre otros múltiples factores por efecto de los repartos sucesorios y en ocasiones por la ausencia de herederos varones. De hecho los datos de que disponemos para reconstruir la trayectoria de los Haro en Cameros y Rioja hasta el acceso al trono de Enrique de Trastamara resultan a veces contradictorios,

\footnotetext{
${ }^{79}$ Da cuenta de los documentos que refieren estas ventas A. GONZÁLEZ BLANCO y H. PASCUAL GONZÁLEZ, Las siete villas del Campo, en tomo al origen de algunas estructuras medievales", "Brocar", 9-2 (1983), pp. 104-105. Se remiten a C. GoICOECHEA, Castillos de la Rioja. Notas descriptivas e históricas, Logroño, 1949, pp. 45-46. La venta del lugar y castillo de Daroca, por Teresa de Almoravil a Rodrigo Alfón de Logroño es de 14-VIII-1337. Consta que esta coinpra y la de Agoncillo las efectuó este caballero logroñés por mandado de Alfonso XI, quien luego le concedió todos los servicios, pedidos y ayudas que correspondiese pagar a los ocho pecheros de Agoncillo y los cuatro de Daroca (Cf. privilegio de Alfonso XI cit. en nota 64). La venta de los derechos en Sotes al concejo de Navarrete está fechada el 14IX-1346.

${ }^{80}$ Dan cuenta indirecta de esta concesión sendos privilegios de Pedro I, fechados en Sevilla 9-XI-1353 y en Villalpando 10-IV-1356, de los que se conserva copia en RAH, Salazar y Castro, D-9, fols. 141 y 142. En M*.T. PENA MARAZUELA y P. LeON TELL, Inventario del archivo de los duques de Frias, I, Madrid, 1955, Casa de Velasco, leg. 23, no. 17-b y 18, se hace referencia a una presunta concesión por Alfonso XI del lugar de Nieva a Juan Alfonso de Haro, de quien lo habria heredado Urraca de Guzmán, que fue la que lo vendió a los Velaseo y Zúñiga. Probablemente se trate de un error, ya que Urraca de Guzmán era nieta de Álvar Díaz de Haro.
} 
y no llegan a aclarar suficientemente hasta qué punto la desaparición del linaje de la vida política regional fue fruto de decisiones políticas de la monarquia, que hubiese decidido confiscarles sus principales señorios en castigo a sus repetidos actos de rebeldía, o resultado de la incapacidad de los representantes de linaje tras la muerte de los tres hijos de Juan Alfonso de Haro I para mantener la posición heredada de sus antepasados.

El hecho de que Enrique II dispusiese libremente del señorío de Cameros y del resto de los lugares que habían pertenecido al señorío de Juan Alfonso de Haro II y sus hermanos, parece avalar la tesis de que fue la monarquía la principal responsable del derrumbe político de los descendientes de los Haro en la segunda mitad del siglo XIV, y en gran medida asi fue, quedando gravado en la memoria colectiva el ajusticiamiento de Juan Alfonso de Haro como el principal factor desencadenante de este derrumbe. $Y$ el hecho de que ni su hijo Alfonso Lopez de Haro ni su nieto Juan Alfonso de Haro III consiguiesen ocupar posiciones de poder destacadas en Rioja y Cameros apunta en este mismo sentido ${ }^{81}$. No obstante, también es cierto que los descendientes de los dos hermanos menores de Juan Alfonso de Haro II continuaron transmitiendose derechos señoriales sobre diversos lugares constitutivos del señorío camerano y que, si bien la monarquía representada en la persona de Enrique II ignoró la existencia de estos titulares y la vigencia de sus derechos, Juan Ramirez de Arellano como beneficiario de la merced del señorío de Cameros tuvo que concertarse con varios de ellos para que renunciasen a sus derechos, e incluso en algunos casos tuvo que renunciar a tomar posesión efectiva de ciertos luga-

\footnotetext{
${ }^{81}$ Aunque la crónica de Alfonso XI indica que Juan Alfonso de Haro II, al morir en 1333, no tenía heredero legítimo, y por ello el rey dio el scñorío de Cameros a sus hermanos, quedándose para si el resto de sus villas, lugares y castillos (Cf. nota 72), se constata que tuvo un hijo, Alfonso López de Haro, y éste a su vez al menos otros dos, Juan Alfonso de Haro III y Alfonso López de Haro. Este último hizo testamento en Villamista, el 14-X-1387, haciendo constar que le pertenecía la mitad del lugar de Pedroso, lugar del monasterio de Santa María de Nájera que había ocupado, durante la minoría de Alfonso XI, Juan Alfonso de Haro II. Paradójicamente fue éste el único lugar en el que los descendientes de este señor de Cameros alegaron disfrutar de derechos señoriales hasta fines del siglo XIV, cuando en origen el legítimo titular era el monasterio de Nájera. Noticias a este respecto en sendos documentos de 1389 referentes al testamento de Alfonso López de Haro II en AHN, Códice 106-B, fols. 344 y 354. Respecto a Juan Alfonso de Haro III, hay que hacer constar que participó en el bando enriqueño en la batalla de Nájera, a pesar de lo cual paradójicamente Enrique II no le hizo merced de ningún señorio ni siquiera del lugar de Pedroso, que él había ocupado con anterioridad, y que sin embargo fue entregado por el nuevo monarca a Lope Martínez de Calderón. Sobre su participación en la batalla, vid. E. GONZALEZ CRESPO, op. cit. p. 397.
} 
res integrados en el señorío camerano y que, además, eran mencionados explícitamente en el privilegio que le concedió Enrique II $^{82}$.

\section{RÉSUMÉ}

Ce travail est une contribution à l'étude du rôle politique de la noblesse dans les differents territoires régionaux de la Castille avant les Trastamaras et, au même temps, une appréciation de l'importance des minorités de Fernando IV et Alfonso XI dans le procès de la consolidation de la noblesse a la tête de la vie politique de leurs propres territoires régionaux. A cet effet, nous avons choisi la branche mineure de la famille des Haro, laquelle a exercé une influence décisive dans la vie politique des territoires de la Rioja Baja et Cameros à partir du règne d'Alfonso $X$ jusqu'à la majorité d'Alfonso XI. Notre attention a été fixée aux trois principaux représentants des Haro qui ont successivement exercé le pouvoir pendant cette période: Alfonso López de Haro, son fils Juan Alfonso de Haro I, et le fils de celui-ci Juan Alfonso de Haro II.

L'analyse des moyens employés par ces trois sujets afin d'élargir les bases de leur exercise su pouvoir nous permet d'identifier aussi les principaux ressorts que, par conséquent, sont entrés en conflit avec eux pour freiner leurs projets d'expansion.

Finalement, il y est aussi analysé le procès du declin de cette famille après que Juan Alfonso de Haro Il a été condamné à mort sous Alfonso XI, l'année 1333.

\section{SUMMARY}

This work is a contribution to the study of the political role of the aristocratic families in the different regions of Castile before the Trastamaras, and also an appreciation of the importance of the minorities both of

\footnotetext{
${ }^{82}$ Vid. nuestro artículo Implantación territorial.
} 
Fernando IV and Alfonso XI in the process of strengthening those families as rulers of politics in their own regions. We have chosen the minor branch of the Haros, a family which had a decisive influence on politics in Rioja Baja and Cameros from Alfonso X until the majority of Alfonso XI. Special attention is given to the three main representatives of the family who successively exercised power in this period: Alfonso López de Haro, his son Juan Alfonso de Haro I, and the son of the latter, Juan Alfonso de Haro II.

Analysis of the different steps taken by these three to broaden the basis of their power also enables us to identify the main groups of opposition to the expansionists projects of the Haros. Finally, the decline of their political power after the death sentence on Juan Alfonso de Haro II, ordered by Alfonso XI in 1333, is duly analysed. 